\title{
Service Quality Analysis of Intercity Bus Service of Pabna-Dhaka Highway
}

\author{
Md. Al-Amin, Md. Shaidul Islam, Md. Shakil Ahammed \\ Civil Engineering Department, Pabna University of Science \& Technology, Pabna, Bangladesh \\ Email address: \\ alamin.ce141109@gmail.com(Md. Al-Amin),septama195@gmail.com (Md. S. Islam), \\ Shakilahmmad5000@gmail.com (Md. S. Ahammed)
}

\section{To cite this article:}

Md. Al-Amin, Md. Shaidul Islam, Md. Shakil Ahammed. Service Quality Analysis of Intercity Bus Service of Pabna-Dhaka Highway. American Journal of Traffic and Transportation Engineering. Vol. 6, No. 4, 2021, pp. 116-127. doi: 10.11648/j.ajtte.20210604.12

Received: July 9, 2021; Accepted: July 19, 2021; Published: August 6, 2021

\begin{abstract}
In developing country like Bangladesh, service quality improvement in public transportation is essential. That is why; we need strategic planning \& adopting a quality management system for improving it. From the bus passengers viewpoints the public bus performance evaluate here. This paper deals with the quality improvement of the public transport system with take into consideration of the principal variables that dominance the perceived quality by users. Investigate factors that are affecting passengers perceived bus performance through an Ordered Probit Model (OPM). Take advantage of the Ordered Probt Model, data is analysed based on 297 samples raised from visibility survey with bus passengers during service testing period in Pabna to Dhaka route. The results of the study indicate that $79.79 \%$ of the respondents were male; $39.70 \%$ were aged between 20-29 years, $45.10 \%$ respondent indicated level of service as good; $50.50 \%$ respondent indicated level of service as moderate; and only 1\% respondent indicated level of service of transit bus as bad. The Model (OPM) represent the quality appraisement process founded on a group of predefined variables. These variables choice is essential since they are used to explain the selection process to be modeled. In addition, the results revealed that punctuality \& reliability, Seat comfort, noise level, physical appearance, frequency of bus service, seat availability and female harassment have a significant relationship with passengers satisfaction because they have a P-value smaller than $\alpha=0.10$ as the significant level is at $10 \%$ and Z-value is greater than 1.64. Attempts to improve on service quality to influence passenger's satisfaction should be directed at those variables. The administration of Pabna city will be benefited from this strategies result consist of useful information to ensure the sustainability of the public transport system.
\end{abstract}

Keywords: Public Transportation, Ordered Probit Model, Customer Satisfaction, Variables Service Quality

\section{Introduction}

Pabna is one of the oldest cities in central Bangladesh. It's the most valuable district of this country having current population of almost 3,011,180. Here founded a historical college, a public university, medical college since then population increased here from different districts of Bangladesh. Moreover, at the meantime public transportation also increased here. At Pabna city roads and railways are the two main mode of transport and Dhaka is about five hours away by road. Railway is not perfect transportation system here, so road or highway is the only essential mode of transport [17]. For this reason increasing number of branded and non-branded (Local) bus companies are engaged in transport business on Pabna to Dhaka route.
Public transport quality depends on several attributes (factors) of the service like as; average travel time and its reliability, transit waiting time, monetary costs which are quantitative, whose effects on bus user's behavior are more difficult to assess like as; riding comfort, information, and security [15].

This research analyses the relationship between passenger satisfaction about overall service and service quality factors, based on needs and expectations that expressed by the public transport services customers [18]. An Order Probit model (OPM) is proposed here which is useful to researchers as a multivariate technique combining regression, factors analysis. Here can be noted that Order Probit and Logit are the discrete choice models that more efficiently characterize the different transport systems quality and provide 
knowledge for use in future policy design [1].

Public transport services should have a sensibility towards the quality of services offered. Users surely will choose good public transport services. Such service is provided to give extra comfort to users in urban and rural areas to move [29]. To increase the quality of service and customer satisfaction it is important to measure how the service provided is realized and to determine customer's expectation. Public transport service quality is related to a series of factors. Customer's satisfaction data mainly obtain from questionnaire that contain those factors of public satisfaction.

Service quality measurement from passengers aspects will depends on their access of the individual factors of the service rendered. Public transport service quality plays an important part in affecting the public's daily transportation mode [10].

The highway connection in Pabna city is not well planned from the long time. Since its one of the old city of Bangladesh here road accessibility insufficient. Though bus service station is associated with, short distance from residences there is inadequate good road network. The city does not have individual bus lane, so it has to emulate for space with other vehicle in the busy and narrow road network, which redacts the travel time longer and the system less flexible [21]. It also take in longer time in loading and unloading passengers at stations. Though recently railway service added on Pabna to Rajshahi route but Pabna to Dhaka route train service not available the urban population that mostly depend on the use of the bus service on Pabna to Dhaka route. To identify the area of need and how to meet it the knowledge will help transport policy makers and city transport planners.

This research has an attempt to find out the service quality attributes, which affects the customer satisfaction in Pabna to Dhaka bus service. Here it is important to identify the service quality attributes to measure customer satisfaction. Moreover, this study attempts to assess the level of customer's bus service affordability and their socio-economic characteristics that affect their demand for bus service in the city.

\section{Literature Review}

In the urban region, transportation is the accumulation of individual trip-making decisions based on the individual travel needs and passengers' mobility during specific periods. The facilities and services in the transportation system are the main factors that allow this mobility to occur [16]. The characteristics of these travel patterns and the facilities and services that support the mobility and accessibility are the basis for understanding the transportation system [19].

There are three different classes of urban travel, like as; Public Transport, Non-motorized Transport, and Private motorized Transport [3]. All of them allow modern cities to exploit the advantages of concentration to provide better goods and services more efficiently and to trade those goods and services in other places, which in turn allow for economic specializations and efficiencies. However, the performance of transportation system in the urban area depends on policy and public investment, and on various daily decisions made by travelers about whether, where, how, and when to travel. Understanding how people make travel choices is the key to understand urban transportation problems and potential solutions [26].

In Pabna, according to services, buses are classified into two types: (1) Counter bus service; and (2) Local bus service. Counter buses have specified stoppages for loading and unloading passengers. Passengers have to purchase ticket before boarding on counter buses. Few of the counter buses are air-condition. Counter bus service only for Pabna to Dhaka route and local bus service for Pabna to Rajshahi, Pabna to Ishwardi, Pabna to Kushtia and others route. Local buses have no defined stoppages. They stop anywhere on the road for loading and unloading passengers.

Road is the main transport mode for Pabna city population to and return from Dhaka. Since bus service is main transport a huge number of branded and non-branded bus companies are engaged in transportation business.

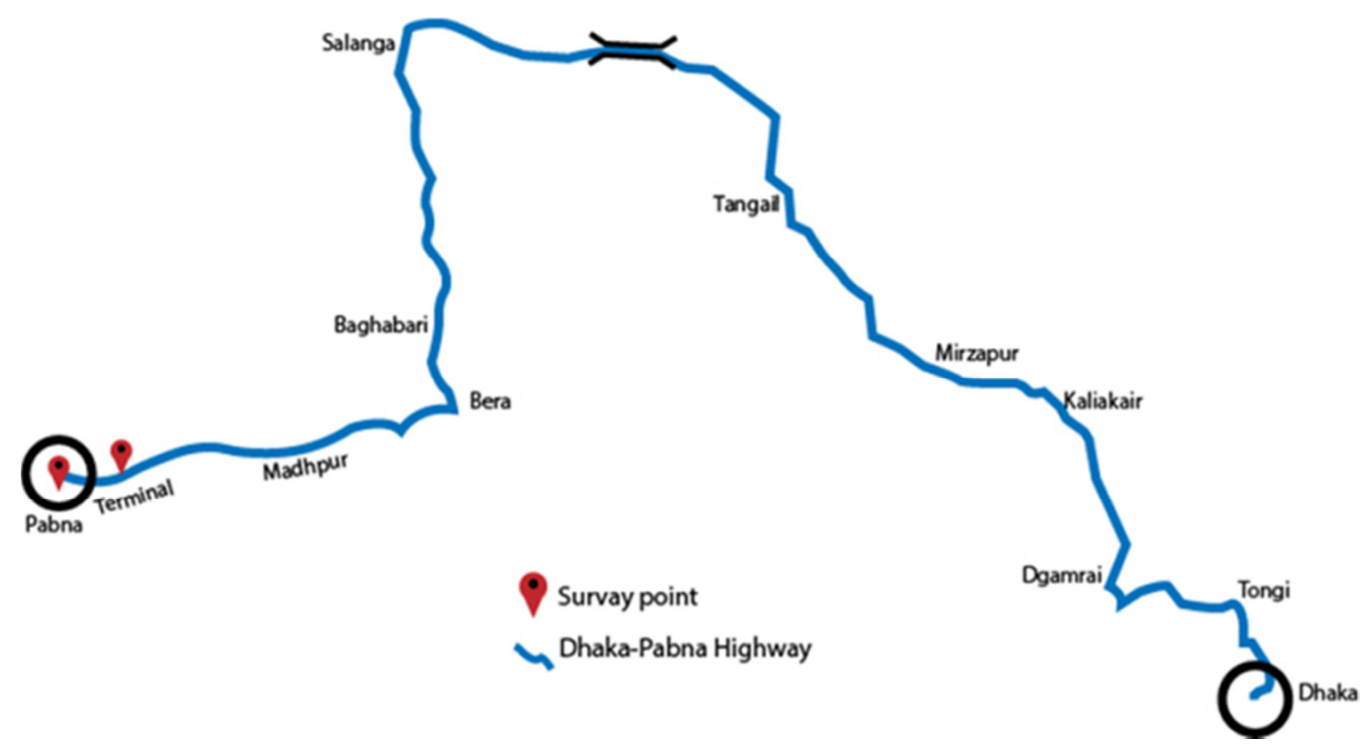

Figure 1. Pabna to Dhaka highway route. 
Many modern systems of public transport performance indicators focus on operating efficiencies instead of service delivery experienced by users such as convenience, comfort, travel time, reliability, and affordability [6].

It is undeniable that level of service in transportation system represents the passengers' perception of the transport performance. Service level concept represents how the service meet the passenger expectation [31]. Various extensive types of attributes, which can be affected by the transport operators and the regulation, can describe the level of service [25].

In addition, people's perception of popular transportation mode influences their decision about the transportation itself. Several key factors considered by passengers in using a particular transportation include safety, comfort, accessibility, reliability, cost, and efficiency. They are important in determining what service type should be considered in a specific area [9].

Perception based on explanatory variables such as service quality and socio-economic factor tend to be convincing factors among the frequent users of the urban transportation system [30].

\section{Methodology}

Some statistical methods have been fruitful for transportation system data analysis. Ordered Probit Model (OPM), Ordered Logit Model (OLM), MNL, Nested Logit Model (NL), Ordered Mixed Logit Model, Heteroscedastic Ordered Logit Model, and logistics regression among of them [5]. Here, Ordered Probit Model (OPM) is the most thoroughly used model. In this model every variables has one co-efficient that means the effects of the particular variable on all injury outcomes are restricted to be the same.

Simplicity is the main convenience of this model. The data analysis for any distributional statistic is easily computed by running a single probability model (like as probit) and using standard packages to compute distributional statistics [20].

Some statistical software including Eviews, SAS, SPSS, R and STATA are mostly used in recent year. In this study, we get decision to use STATA as our statistical software and it has to offer being less expensive. This software allows us to write code or use menus to perform our analysis.

About 297 observations in our data set were used in the STSTA software. Through the software we find out that, our model is statistically significant because here chi square ratio is 102.59 and P-value is 0.000 . Moreover, the pseudo R square of 0.2646 is also given.

\subsection{Conceptual Framework}

Conceptual framework explains the concept, assumption, expectation, beliefs, and theories that informs by variables and indicators and recognizes the connection between them as the basis of the research [23].

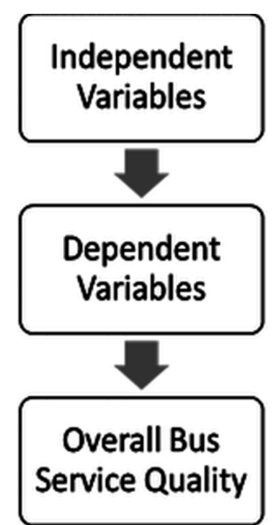

Figure 2. Conceptual Framework for Ordered Probit Model.

In this research, the level of service is elaborated to detail the safety, comfort, travel time, security, availability, punctuality \& reliability. By deeply evaluating the level of service issue from public bus user perception, the determinant factors for service quality can be studied.

\subsection{Description of Ordered Probit Model}

In this case, of bus service quality Ordered data models are based on inventing dependent variables into discrete quantitative data [28]. The model is built upon a latent regression that is expressed as follows:

$$
U_{i}=X_{i}^{\prime} \beta+\xi_{i}
$$

Here,

$U_{i}$ Corresponds to the dependent variables that is a function of a series pf parameters and it multiply the bus service characteristics. This variables coded as 1, 2, 3, 4 and 5 ,

$X_{i}{ }^{\prime}$ Corresponds to the independent variables,

$\beta$ Corresponds to the vector of co-efficient parameters.

$\xi_{i}$ Defines the error that executed from the observations. The random variable $\xi_{i}$ is obtained as a known cumulated distribution function.

The characteristics answers of surveyed users give censored information from reality. Every bus user decides their satisfaction level with the service, so it's impossible to establish a criterion. Users would like to choose the option that is familiar to their quality perception [7].

Here, bus users choose one of the following desires:

1. Very Bad

2. $\mathrm{Bad}$

3. Moderate

4. Good

5. Excellent

This discretization is obtained by dividing the real space into bands using parameters. Every bands is connecting with numerical value. In this way the following response options:

1 . Very Bad $\rightarrow 1$,

2. $\mathrm{Bad} \rightarrow 2$,

3. Moderate $\rightarrow 3$, 
4. Good $\rightarrow$ 4,

5. Excellent $\rightarrow 5$

In this Model (OPM), the dependent variable takes more than two values with a natural ordering. The model able to account for the ordinal nature of the dependent variable though the result is discrete. Here Ordered Logit model is failed to do this.

At equation, no (1) to fit the parameter vector the model artifice will use the observation on $U_{i}$. Here $X_{i}{ }^{\prime}$ is a set of independent variables, the bus performance $U_{i}$ falls in a category $\mathrm{j}$ if $\mu \mathrm{j}-1<U_{i}{ }^{*} \leq \mu \mathrm{j}$ here noted that, $\mathrm{j} \in \mathrm{J}=\{1,2,3$, $4,5\} . U_{i}$ is the bus performance data that engaged with the underlying observation $U_{i}{ }^{*}$. This observation $U_{i}{ }^{*}$ crosses orbit $\mu \mathrm{j}$. The difference between the first and second result may be not equal as between the second and third difference result [4].

The orbit value between the first lowest and the next lowest group are always to $\mu 1=0$. Its main reason is, a shift in the constant term cannot be separated from a shift in the orbit values and here we only estimate the constant values. Now at equation no (2), the observed dependent variable can be expressed as following:

$$
U_{i}=\left\{\begin{array}{c}
1 \text { if } U_{i} * \leq 0 \text { (Very bad bus perfonnance) } \\
2 \text { if } 0<U_{i} * \leq \mu_{2} \text { (Bad bus performance) } \\
3 \text { if } \mu_{2}<U_{i} * \leq \mu_{3} \text { (Moderate bus perfonnance) } \\
4 \text { if } \mu^{3}<U_{i} * \leq \mu^{4} \text { (Good bus performance) } \\
5 \text { if } \mu_{4}<U_{i} * \text { (Excellent bus perfonnance) }
\end{array}\right.
$$

The bus performance probability $P_{n}$ to decline in a group $j$ $\in \mathrm{J}$ is following the equation (3).

$$
\mathrm{P}_{\mathrm{n}}\left(U_{i}=\mathrm{j}\right)=\mathrm{F}\left(\mu_{\mathrm{j}}-\beta \mathrm{x}_{\mathrm{n}}\right)-\mathrm{F}\left(\mu_{\mathrm{j}-1}-\beta \mathrm{x}_{\mathrm{n}}\right)
$$

Where,

$\mathrm{P}_{\mathrm{n}}\left(U_{i}=\mathrm{j}\right)$ is define as bus performance probability into a group $j$,

$F($.$) is define as cumulative normal distributiion function,$

$\mu_{j} \& \mu_{j-1}$ are corespondents to upper \& lower orbit parameters for group $j$.

The $\log$ function can be defined based on the sum of individual log probability inn equation no (4).

$$
\operatorname{LL}(\theta)=\sum_{\mathrm{n}=1}^{\mathrm{N}} \log \mathrm{p}_{\mathrm{n}}\left(U_{i}=\mathrm{j}\right) \forall \mathrm{j} \in \mathrm{J}
$$

The OPM model consist of main two sets of parapeters:

Co-efficient parapeters indicate the importance of each explanatory variable in determining the associate probability of passengers to evaluate better bus performance [27].

Constant term and other orbit values (as like: $\mu_{2}, \mu_{3}$, and $\mu_{4}$ ) define the range of normal distrubution.

Here, the sum of the marginal effects for each explanatory variable equals to zero. When interpreting the signs of the estimated co-efficient in this OPM model must be careful since they might have different effects on the probabilities of each group of bus performance.

\subsection{Study Methodology}

Data collection (on both primary and secondary data) approach incorporating a questionnaire survey that is the first step of this study methodology. To identify the service quality attributes we are taken into consideration various group discussion, bus operators and policy makers. After cross checking the primary \& secondary data we identified the service quality attributes for Pabna to Dhaka route bus users.

Then, a questionnaire was designed that consist the following items such as, safety of services, travel cost, Seat comfort, travel time, Cleanliness, Security of goods, Punctuality \& reliability and so on. Here random sampling was used in the questionnaire. Purposive sampling technique was evaluate in this questionnaire because it enabled us to choose respondents directly affected by accessibility problem.

Now at this step separate choice models need to apply to determine predictions about bus user's behavior. Bus user plays a very vital role in this process of modeling and if properly calibrated, they allow making predictions about next steps of the study system [11]. We use random parameters to estimate the OPM model. Collected data is filtered for anomalies and OPM model is developed to understand overall bus level of service.

\subsection{Sample}

Considering time and cost, it is impossible to cover the entire population of Pabna city and is difficult to make direct survey with them. For that, a random sample of the population is selected. However, in this case both sampling error and selection error have to be taken into account. This both error can generate changes in the results of an investigation. In this method, each element has a known probability of becoming a part of the sample. This study is based on total 297 samples with 19 SQ parameters.

In questionnaire survey, our first target is collect information about user's socioeconomic characteristics such as age, gender, occupation and their purpose for traveling. Then we give focuses on 19 SQ attributes those are meticulously selected for the scenario of Pabna city. Thirdly, collect benchmark points on a quantitative scale of 1 to 5 to rate overall SQ, where 1 and 5 corresponds to very bad and excellent. Finally, the users were asked to select 18 attributes upon which they have decide the SQ rating of a bus service.

\subsection{Description of Variables and Indicators}

In this research, the characteristics of transport services have been operationalized as the level of service that includes the safety, comfort, availability, reliability, travel cost, Seat comfort, Cleanliness, Security of goods, Punctuality \& reliability and so on. The table below shows the operationalization of concepts with the variables and measurable indicators. 
Table 1. Variable description table.

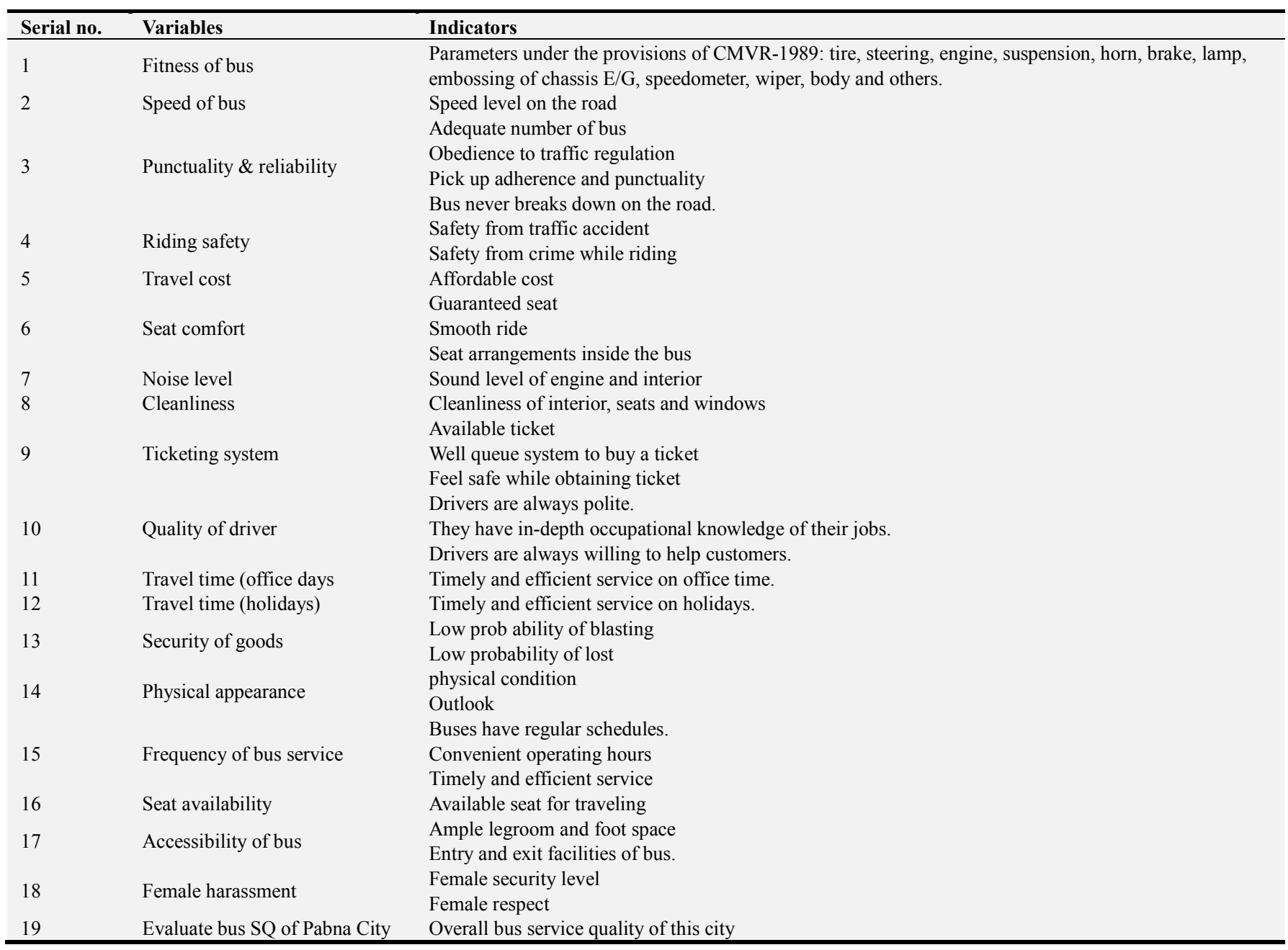

Some indicator to measure the service level delivery may be provided in a different way [22]. Specific description and level of service range for several service measures as follows:

\section{Service Availability}

This service category reflects the characteristics of vehicle path and coverage, number of fleets, travel time, services option, service accessibility, and waiting time. Service availability and accessibility is a factor that determines whether a public transport becomes favorable or less likely to be an option for the passenger [14]. Ideally, the service can be reached in moderate walking distance from departure location to arrival location.

\section{Service Reliability}

Reliability of the public transport services can be interpreted as the ability to maintain consistent travel time and punctual schedule. Service reliability in terms of travelling time is a significant component that shapes the perspective of transportation means. Other important components are time spent in waiting, walking, and transferring modes, which are viewed as time-consuming compared to the time spent in the vehicle [2].

Comfort

Comfort in public transport means the passengers are provided with physically good vehicle condition, clean seats, smooth ride, and additional amenities that support passengers' trip experience. Seat arrangement inside the bus is responsible for comfort traveling. Passenger demand for comfortable seat that influence the level of bus service. In Pabna to Dhaka, route normal seat arrangement inside the bus is showing below:

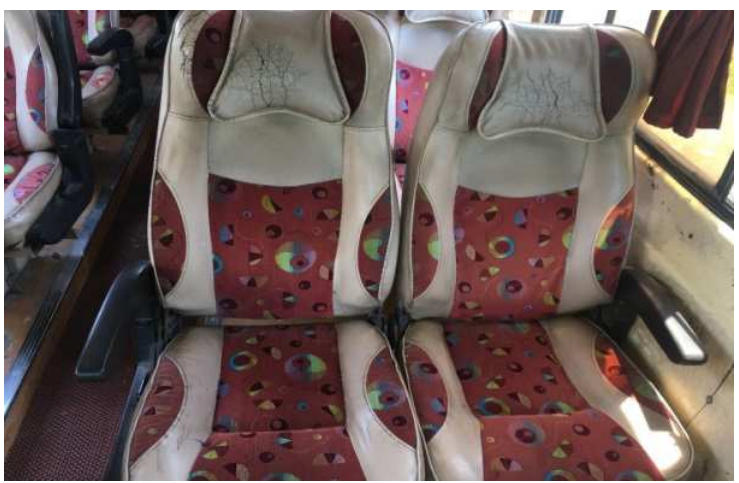

Figure 3. Seat arrangement of bus.

\section{Safety and Security}

The safety and security aspect is safety from the accident, crime, and feeling of security from the behavior of other 
people. Safety during the travel may not be a factor that affects the modal choice. Likewise, the possibility of becoming a victim of an accident or being involved in a crime incident is not considered as the determinant of the transport option [12]. However, when a passenger is asked about the safety and security importance, this factor is considered as enormously significant in the public transport operation.

\section{Travel Time}

Bus drivers and road conditions could cause large differences in journey times. Free flow travel speed is one of the factors that affect travel time. Another main factor related to travel time is holiday and special incidents, signal delay, weather conditions and traffic flow [8]. Travel time data can be collected through a verity of methods. A bus user may register time using his watch.

\section{Travel Cost}

When branded and non-branded buses are conducting in the same city in corresponding situations, this difference in cost persuades. All branded and AC service bus operating through high cost. At the meantime, public bus service is less costly on accordance private bus service.

\section{Ticketing System}

Ticketing is a system of payment for bus passengers and the collection of fees to bus operators. There are many types of bus ticketing system such as; paper tickets, cash, tokens, smartcard ticketing system and so on. Now a days online ticketing system is more easy and comfortable for passengers. Bus passenger can collect it with timely and it secured.

\section{Female Harassment}

Recent time on public bus female harassment is comprehensively high. College \& university girls, office \& industry going women are the main victim of this harassment. They feel worried at the time of public bus using even day or night. In a developing country like Bangladesh, this problem makes a major concern for government.

Noise Level

Traffic noise occurs in the busy traffic movement area. In this case the principal parameters such as; velocity surface roughness index, traffic flow rate, distance and so on. This kind of factors are compressively in Bangladesh.

\section{Cleanliness}

In branded and non-branded bus, the cleanliness situation is different. Maximum time non-branded local bus contains food waste, waste papers, plastic drink bottle. At seat place and seat ramp dust and spoils looking mischievous.

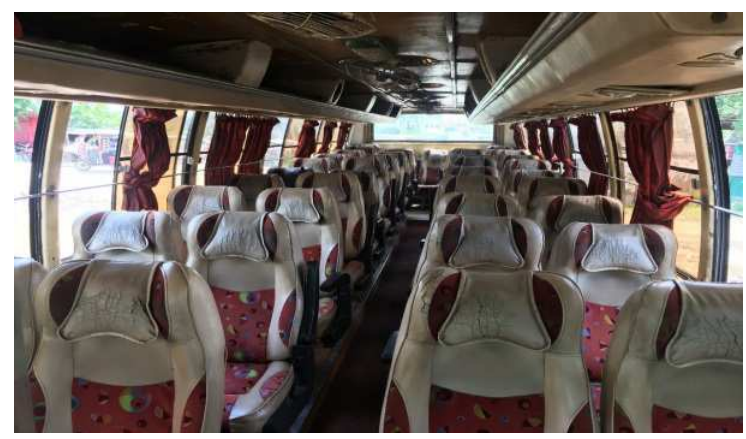

Figure 4. Inside of a bus.

\section{Accessibility of Bus}

Bus should have proper ramps that passenger can easily in or out into the bus. Accessing into bus have priority for senior citizens and passengers with disabilities. A digital sign at the front of each bus tells you when your stop is approaching which is available in the developed country.

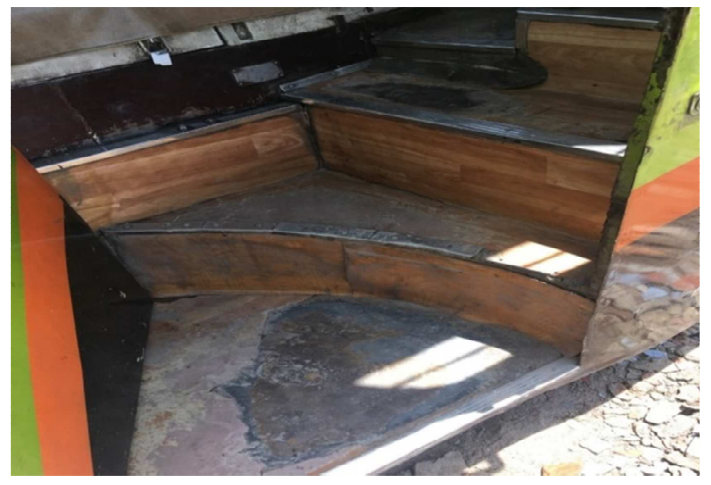

Figure 5. Accessing ramp of bus.

\section{Quality of Driver}

Bus driver plays a vital role for service quality maintenance. Their socio-economic characteristic and driving habit affects service performance [13]. Sometimes passengers raise complain against driver behaviors. Many drivers have bad habit like smoking, drinking, not wearing seat belt, using phone, talking with others at the time of driving. In technical issue, maximum derivers are not well educated, they have not any concern about traffic rules, and they do not obey with traffic police. In the circumstance, road accident occur and reduce passenger satisfaction level in their bus service. Exact solutions for the problem will be that, driver should be taught about better socio-economic characteristics, being responsible about their duty. Driving training is must for fresher that will helpful for reduce accident on the high way.

Physical Appearance

Physical appearance correspondent to physical condition and outlook of a bus. It has influence on level of bus service.

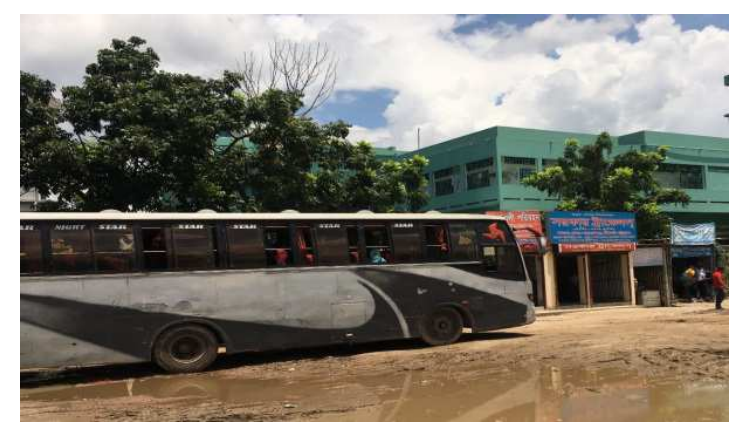

Figure 6. Outlook of a bus.

\section{Data Description and Preliminary Statistics}

\subsection{Interview Survey}

This research data obtained from an interview survey 
during the period of $9^{\text {th }}$ to $20^{\text {th }}$ February 2019. Three welltrained interviewers conducted the survey with 297 bus passengers. This questionnaire survey consist with passenger's socio-economic characteristics, trip purpose with in total 18 number of characters. The subjective amends scores on overall bus performance and attributes using 1 to 5 point consecutive scale.

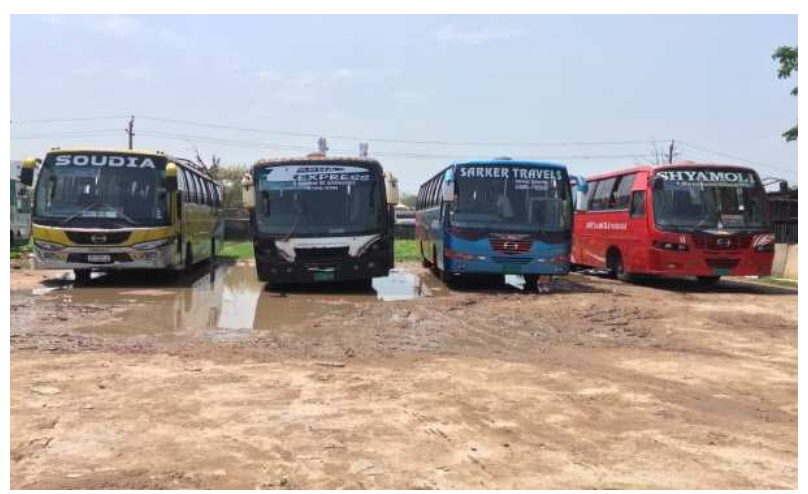

Figure 7. Some bus of Serving.

\subsection{Research Strategy}

Travel behavior in this research is based on user perception. This study employs a survey research strategy that is used to describe the characteristics of particular cases or aspects in the larger population, which involves quantitative information, and several independent variables that strongly affect the dependent variables. Survey research is appropriate for the study in which the central research questions are "how," "what," and "why." Specifically, this study seeks to address the most influential factor in Level of Service and perception that affects the commuters' satisfaction [19]. This is why the survey research strategy method is the most suitable mechanism to use. In this research collects data from a sample population at a single time, comparatively in a short period and performs evaluations across the concerned variables.

The use of survey to complete research may be confronted with some limitations and challenges. For instance, the ambiguous responses and omission of responses in certain questions. The imperfect replies of the respondent may occur because of the education background, making it difficult to generalize information on variables, and making it hard to measure. Particularly, the variables of perception of the level of service, which plays a significant role, as the determinant in the service quality research is hard to be, delivered eloquently trough the survey method because it involves a large number of questions and respondents. Once the survey process is started, it will be difficult to modify the questions if some questions need to be eliminated or are ambiguous to be understood by the respondent [32].

\subsection{Respondent Characteristic}

Majority of the respondents was male and 20.21 percent were female (Figure 8). Figure 9 shows that $28.6 \%$ of the respondents are students, $20.2 \%$ are private job holder, $11.8 \%$ are govt. job holder, $9.1 \%$ of the respondents are housewife, labor are $11.8 \%$ and $18.5 \%$ of the respondents are businessman. Age ordination is $7.4 \%, 39.7 \%, 30 \% \& 15.85 \%$ of the respondents fall in the group of 15 to 19 years, 20 to 29 years, 30 to 39 years, 40 to 49 years, and more than 50 to 60 years age group (Figure 10). According to $3.4 \%$ of the respondents the SQ is excellent; $45.10 \%$ respondent indicated level of service as good; $50.50 \%$ respondent indicated level of service as moderate; and only $1 \%$ respondent indicated level of service of transit bus as bad (Figure 11).

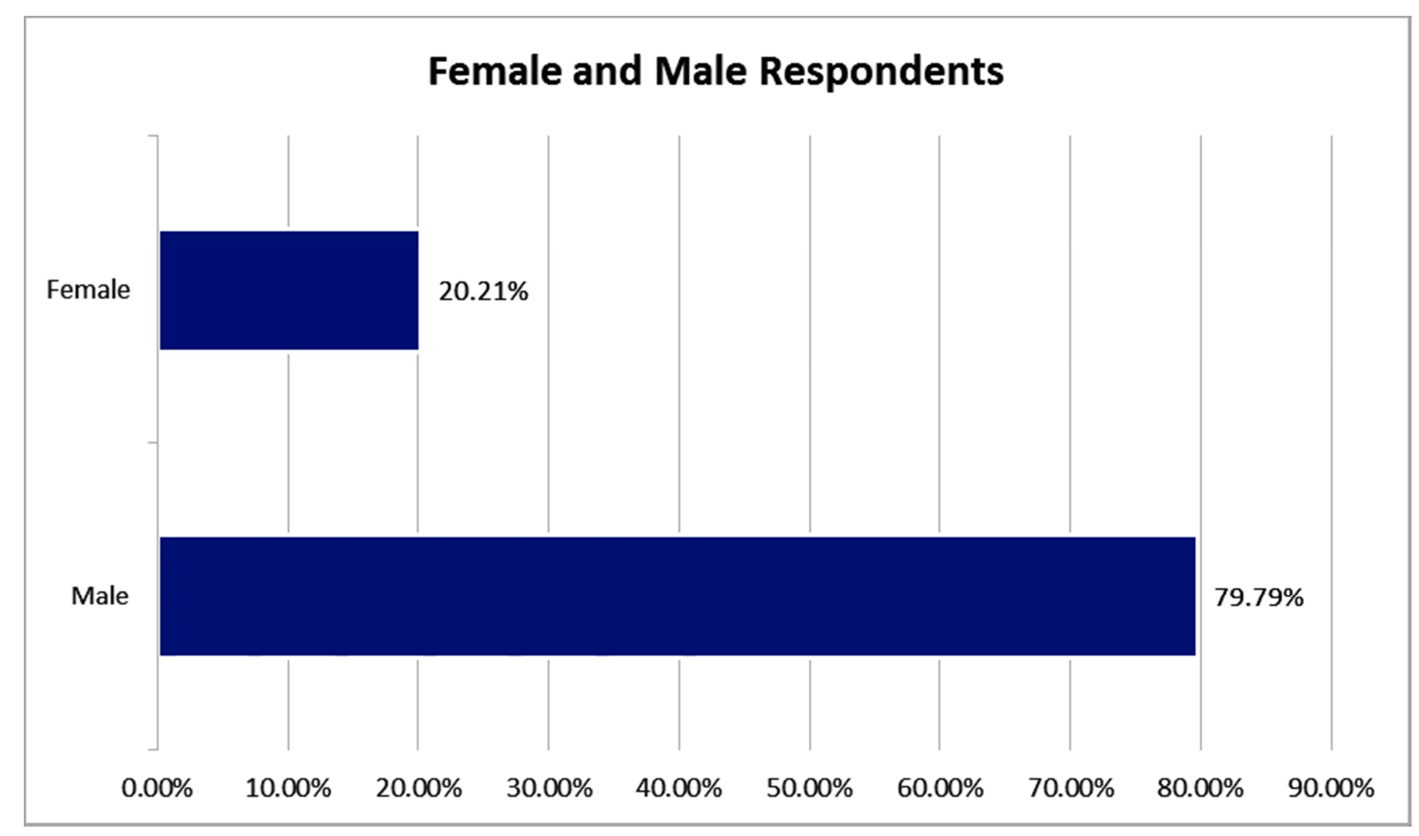

Figure 8. Female and Male Respondents.

The respondents percent of Male were $79.79 \%, 20.21 \%$ of the respondents were female. 


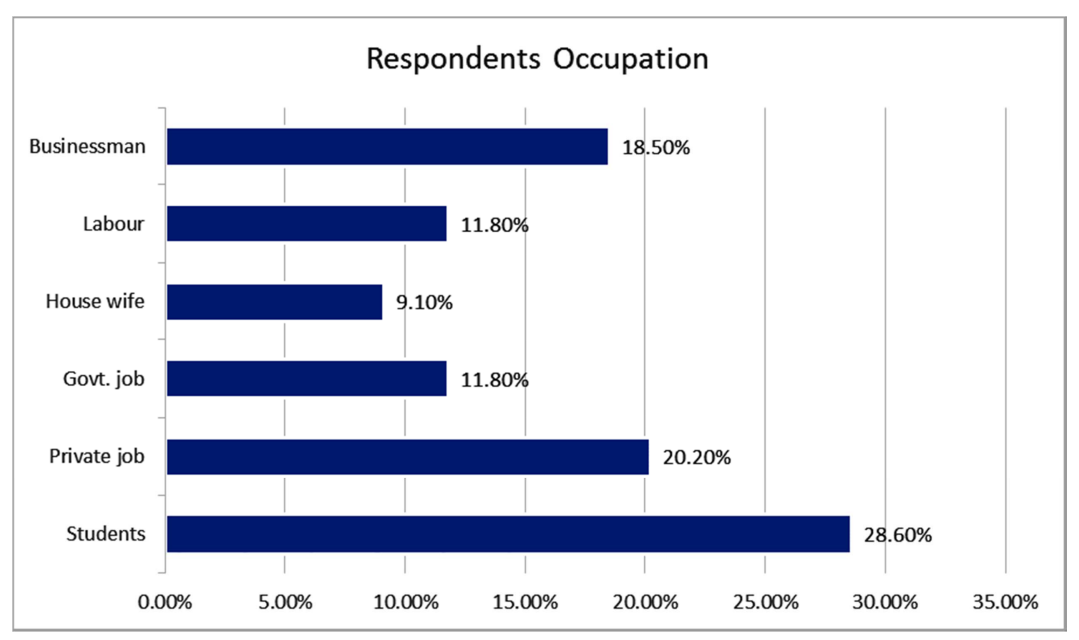

Figure 9. Respondents Various Occupations.

The respondents percent of students were $28.60 \%, 20.20 \%$ percent respondents were Private job, $11.80 \%$ percent respondents were Government job, 9.10\% percent respondents were Housewife 11.80\% percent respondents were Labor, $18.50 \%$ percent respondents were businessman.

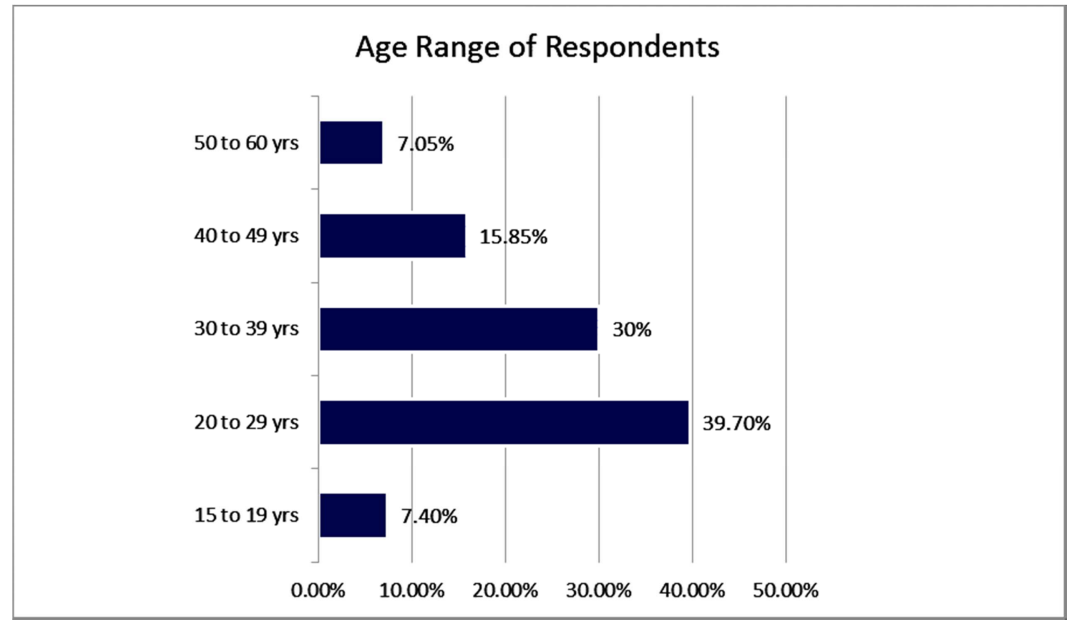

Figure 10. Age Range of Respondents.

$7.40 \%$ respondents fall in the group of 15 to 19 years, $39.70 \%$ respondents fall in the group of 20 to 29 years, $30 \%$ respondents is in the group of 30 to 39 years, $15.85 \%$ respondents is in the group of 40 to 49 years, $7.05 \%$ respondents fall in the group of 50 to 60 years.

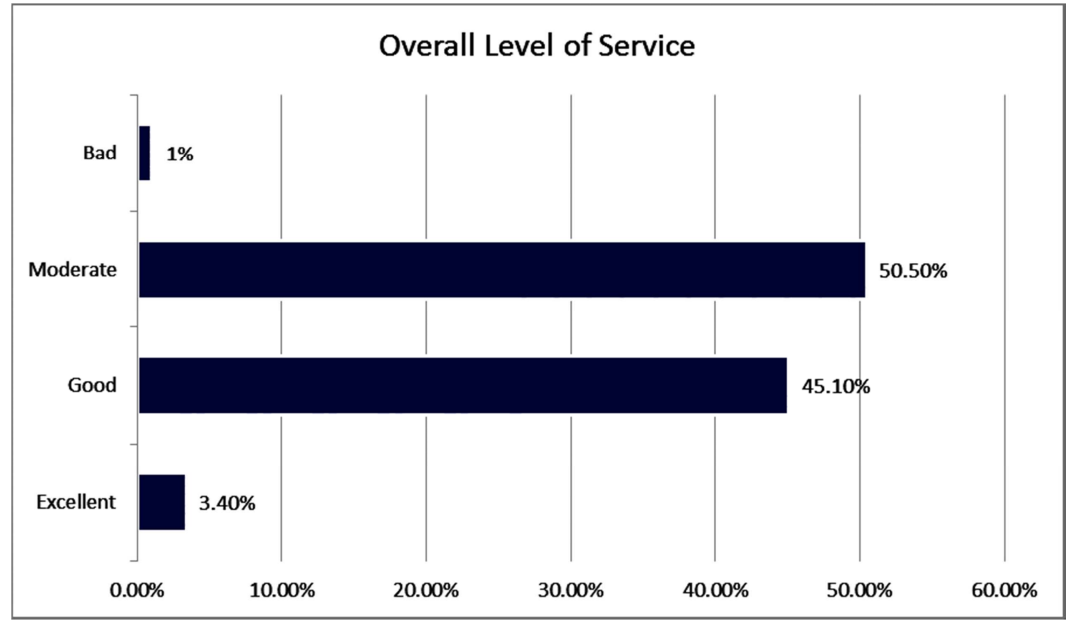

Figure 11. Overall Level of Service. 
According to $3.40 \%$ of the respondents the SQ is excellent, $45.10 \%$ respondents indicated level of service as good; $50.50 \%$ respondent indicated level of service as moderate; and only $1 \%$ respondent indicated level of service of transit bus as bad (Figure 11).

\section{Empirical Model Result}

In this research, 18 number of independent service quality variables like as fitness, speed, punctuality \& reliability, safety, travel cost, seat comfort, noise level, cleanliness, ticketing system, Quality of driver, Travel time (office days), Travel time (holidays), Security of goods, physical appearance, frequency of bus service, seat availability, accessibility, female harassment were taken into account to impact passengers satisfaction. These variables were analyzed through ordered probit regression analysis. The outcome reveal a maximum co-efficient of 0.675 .

Table 2. Ordered Probit Regression Result.

\begin{tabular}{|c|c|c|c|c|c|c|}
\hline \multicolumn{3}{|l|}{ Ordered probit regression } & \multirow{2}{*}{\multicolumn{4}{|c|}{$\begin{array}{l}\text { Number of obs }=297 \\
\text { Wald chi2 }(18)=102.59\end{array}$}} \\
\hline \multirow{3}{*}{\multicolumn{3}{|c|}{ Log pseudo likelihood $=\mathbf{- 1 8 8 . 8 5 4 0 7}$}} & & & & \\
\hline & & & \multicolumn{4}{|c|}{ prob $>$ chi $2=0.0000$} \\
\hline & & & \multicolumn{4}{|c|}{ pseudo $\mathrm{R} 2=0.264$} \\
\hline Evalution of Quality & Coef. & Robust std. Err. & $\mathbf{z}$ & $\mathbf{P}>[\mathbf{z}]$ & \multicolumn{2}{|c|}{ [95\% Conf. Interval] } \\
\hline Fitness of bus & -0.013879 & 0.107617 & -0.13 & 0.897 & -0.22480 & 0.19705 \\
\hline Speed of bus & 0.010218 & 0.131147 & 0.08 & 0.938 & -0.24683 & 0.26726 \\
\hline Punctuality \& reliability & 0.279205 & 0.120761 & 2.31 & 0.021 & 0.04252 & 0.51589 \\
\hline Riding safety & 0.003868 & 0.118300 & 0.03 & 0.974 & -0.22799 & 0.23573 \\
\hline Travel cost & -0.116849 & 0.115305 & -1.01 & 0.311 & -0.34284 & 0.10915 \\
\hline Seat comfort & 0.321538 & 0.118508 & 2.71 & 0.007 & 0.08927 & 0.55381 \\
\hline Noise level & -0.214698 & 0.117867 & -1.82 & 0.069 & -0.44571 & 0.01632 \\
\hline Cleanliness & 0.110515 & 0.125809 & 0.88 & 0.380 & -0.13607 & 0.35710 \\
\hline Ticketing system & 0.156297 & 0.104232 & 1.50 & 0.134 & -0.04799 & 0.36059 \\
\hline Quality of driver & -0.017130 & 0.118928 & -0.14 & 0.885 & -0.25023 & 0.21596 \\
\hline Travel time (office days & 0.127891 & 0.147446 & 0.87 & 0.386 & -0.16110 & 0.41688 \\
\hline Travel time (holidays) & 0.073426 & 0.113033 & 0.65 & 0.516 & -0.14811 & 0.29497 \\
\hline Security of goods & -0.083531 & 0.115956 & -0.72 & 0.471 & -0.31080 & 0.14374 \\
\hline Physical appearance & 0.428364 & 0.149000 & 2.87 & 0.004 & 0.13633 & 0.72040 \\
\hline Frequency of bus service & 0.324527 & 0.132294 & 2.45 & 0.014 & 0.06524 & 0.58282 \\
\hline Seat availability & 0.323824 & 0.141150 & 2.29 & 0.022 & 0.04717 & 0.60047 \\
\hline Accessibility of bus & 0.010321 & 0.160088 & 0.06 & 0.949 & -0.30345 & 0.32409 \\
\hline Female harassment & 0.674941 & 0.137018 & 4.93 & 0.000 & 0.40639 & 0.94349 \\
\hline /cut 1 & 5.595788 & 1.003358 & & & 3.62924 & 7.56233 \\
\hline /cut 2 & 8.981691 & 1.110743 & & & 6.80468 & 11.15871 \\
\hline /cut 3 & 11.508650 & 1.224125 & & & 9.10941 & 13.90789 \\
\hline
\end{tabular}

At $95 \%$ confidence level, many explanatory variables are statistically significant. The actual credit of the models for bus performance in terms of pseudo $R^{2}$ value is 0.2646 . The model result shows in the table 2 . Indicate a positive coefficient score for 13 independent variables. Others variables (fitness, travel cost, noise level, driver quality, security of goods) evaluate negative co-efficient. Out of the 13 independent variables with positive coefficients, punctuality $\&$ reliability, seat comfort, Physical appearance, frequency of bus service, seat availability and female harassment were invent as significant for passenger satisfaction in the bus service quality.

The table 2. Further indicates that,

For fitness of bus, the significant P-value is 0.897 . This value is higher than $\alpha=0.10$, as at $10 \%$ significant level. Moreover, the $\mathrm{Z}$-value is $\mathrm{Z}=-0.13$, that is less than 1.64. This proves that fitness of bus dimension does not influence satisfaction. Therefore, significant relevance not exist between bus fitness and passenger satisfaction.

For speed of bus the significant $\mathrm{P}$-value as shown in the table is $\mathrm{p}=0.938$ which is greater than $\alpha=0.10 \%$. As at $10 \%$ significant level, and its $\mathrm{Z}$-value is $\mathrm{Z}=0.08$. It means that speed of bus does not influence the passenger's satisfaction. Therefore, significant relevance not exist between speed of bus and customers.

For punctuality \& reliability $\mathrm{P}$ value is $\mathrm{P}=0.021$ which is less than $\alpha=0.10$, and $Z=2.31$ is greater than 1.64 . This proves that punctuality $\&$ reliability dimension does influence customer's satisfaction. Therefore, significant relevance exist between punctuality \& reliability and passenger's satisfaction.

For riding safety $\mathrm{P}$ value is $\mathrm{P}=0.974$ which is greater than $\alpha=0.10$, and $Z=0.03$ is less than 1.64. This proves that riding safety dimension does not influence customer's satisfaction. Therefore, significant relevance not exist between riding safety and customer satisfaction.

For travel cost $\mathrm{P}$ value is $\mathrm{P}=0.311$ which is greater than $\alpha$ $=0.10$, and $Z=-1.01$ is less than 1.64. This proves that travel cost dimension does not influence customer's satisfaction. Therefore, significant relevance not exist between travel cost and passengers satisfaction.

For seat comfort $\mathrm{P}$ value is $\mathrm{P}=0.007$ which is less than $\alpha=$ 0.10 , and $Z=2.71$ is greater than 1.64 . This proves that seat comfort dimension influences customer's satisfaction. 
Therefore, significant relevance exist between Seat comfort and customer satisfaction.

For noise level $\mathrm{P}$ value is $\mathrm{P}=0.069$ which is less than $\alpha=$ 0.10 , and $\mathrm{Z}=-1.82$ is greater than 1.64 . This proves that noise level dimension influences customer's satisfaction. Therefore, significant relevance exist between noise level and customer satisfaction.

For cleanliness $\mathrm{P}$ value is $\mathrm{P}=0.380$ which is greater than $\alpha$ $=0.10$, and $Z=0.88$ is less than 1.64 . This proves that Seat cleanliness does not influence customer's satisfaction. Therefore, significant relevance not exist between cleanliness and customer satisfaction.

For ticketing system $\mathrm{P}$ value is $\mathrm{P}=0.134$ which is greater than $\alpha=0.10$, and $Z=1.50$ is less than 1.64. This proves that ticketing system dimension does not influence customer's satisfaction. Therefore, significant relevance not exist between ticketing system and customer satisfaction.

For quality of driver $\mathrm{P}$ value is $\mathrm{P}=0.885$ which is greater than $\alpha=0.10$, and $Z=-0.14$ is less than 1.64 . This proves that quality of driver dimension does not influence customer's satisfaction. Therefore, significant relevance not exist between quality of driver and customer satisfaction.

For travel time (office days) $\mathrm{P}$ value is $\mathrm{P}=0.386$ which is greater than $\alpha=0.10$, and $Z=0.87$ is less than 1.64. This proves that travel time (office days) dimension does not influence customer's satisfaction. Therefore, significant relevance not exist between travel time (office days) and customer satisfaction.

For travel time (holidays) $\mathrm{P}$ value is $\mathrm{P}=0.516$ which is greater than $\alpha=0.10$, and $Z=0.65$ is less than 1.64. This proves that travel time (holidays) dimension does not influence customer's satisfaction. Therefore, significant relevance not exist between travel time (holidays) and customer satisfaction.

For security of goods $\mathrm{P}$ value is $\mathrm{P}=0.471$ which is greater than $\alpha=0.10$, and $Z=-0.72$ is less than 1.64 . This proves that security of goods dimension does not influence customer's satisfaction. Therefore, significant relevance not exist between security of goods and passengers satisfaction.

For physical appearance $\mathrm{P}$ value is $\mathrm{P}=0.004$ which is less than $\alpha=0.10$, and $Z=2.87$ is greater than 1.64. This proves that physical appearance dimension influences customer's satisfaction. Therefore, significant relevance exist between physical appearance and customer satisfaction.

For frequency of bus service $\mathrm{P}$ value is $\mathrm{P}=0.014$ which is less than $\alpha=0.10$, and $Z=2.45$ is greater than 1.64 . This proves that frequency of bus service dimension influences customer's satisfaction. Therefore, significant relevance exist between frequency of bus service and customer satisfaction.

For seat availability $\mathrm{P}$ value is $\mathrm{P}=0.022$ which is less than $\alpha=0.10$, and $Z=2.29$ is greater than 1.64 . This proves that seat availability dimension influences customer's satisfaction. Therefore, significant relevance exist between seat availability and customer satisfaction.

For accessibility of bus $\mathrm{P}$ value is $\mathrm{P}=0.949$ which is greater than $\alpha=0.10$, and $Z=0.06$ is less than 1.64 . This proves that accessibility of bus dimension does not influence customer's satisfaction. Therefore, significant relevance not exist between accessibility of bus and customer satisfaction.

For female harassment $\mathrm{P}$ value is $\mathrm{P}=0.000$ which is less than $\alpha=0.10$, and $Z=4.93$ is greater than 1.64. This proves that female harassment dimension influences customer's satisfaction. Therefore, significant relevance exist between female harassment and customer satisfaction.

In the other hand, for female harassment significant $\mathrm{P}$ value is $\mathrm{P}=0.00$, stated as lowest value and $\mathrm{Z}$ - value is $\mathrm{Z}=$ 4.93 and stated as the highest value. It means that female harassment is the most influential dimension as compare to the other 17 dimensions.

Now it obtain that riding safety, travel cost, noise level, cleanliness, ticketing system, quality of driver, travel time (office days) travel time (holidays), security of goods, and accessibility of bus dimension does not influence the passengers satisfaction and significant relevance not exist among those variables and customer satisfaction.

Again, Seat comfort, physical appearance, frequency of bus service, seat availability and female harassment dimension does influence the passenger's satisfaction and significant relevance exist among those variables and customer satisfaction.

\section{Conclusion}

The result of this research, offers instigating direction in evaluating bus service quality, some abridgment is also recognized. The sample size was very small where immensity of the bus users. Data collection also had a gender bias; female passengers were not feel comfort to answer the questionnaire. Moreover, we tried to collect data from all kind of passengers and from different location of pabna city, so that sample data exist the real situations.

The findings indicated that service quality variable as if fitness of vehicles influences the customer satisfaction most. Most of the passenger's opinions were positive about fitness of vehicles and physical appearance. However, some of them were concern in the question of vehicle fitness. According to their view some local bus are unfit for this route. In this route, bad surface quality of road is responsible for low speed of bus. Result shows goods security and respect providing by public bus in this city stated as satisfied. They have concerned about driver quality as in-depth occupational knowledge of their jobs and about service facilities inside the bus. Road accident is very common phenomenon in this route. Passengers believe that most of the accident occurs due to drivers in this route. Other hand, the service quality variables punctuality \& reliability, Seat comfort, physical appearance, noise level, seat availability influence the customer satisfaction. The ticketing system should be digitalized to fulfill their satisfaction. Overall, it can be told that most of the passengers are satisfied with service quality of buses in Dhaka- route. Results also indicate that university and college students could use bus service more frequently than others customers. At off day like Friday and Saturday the usage strongly engaged with this way. 
However, it is recommended that operators amplify interest in improving this sector, making it more useful to passengers. Administration including the police, municipal and pabna district assembles should effort to select qualified bus drivers and cooperate to maintenance bus operators policy. Proper training and workshop need to conduct for driver and driving stuffs to improve their operations.

If it possible to take this necessary step and conduct a customer satisfaction survey on spot that's give a significant notice to passenger. They will start to believe that bus operators are aware about maintaining customer's satisfaction. After that, this survey result contain customers satisfaction can use for their advertising and spread the bus service. Moreover, operators take action to improve about which customers are not satisfied.

\section{References}

[1] Abdel-Aty, M. A. (2001). Using ordered probit model to study the effect of ATIS on transit ridership. Transportation Research C, 9, pp. 265-277.

[2] AVINERI, E. (2004). A Cumulative Prospect Theory Approach to Passengers Behavior Modeling: Waiting Time Paradox Revisited. Journal of Intelligent Transportation Systems, 8 (4), 195-204. Doi: 10.1080/15472450490523856.

[3] De Oña, J., De Oña, R., \&Calvo, F. J. (2012). A classification tree approach to identify key factors of transit service quality. Expert Systems with Applications, 39 (12), 11164-11171. doi: 10.1016/j.eswa.2012.03.037.

[4] De Oña, J., De Oña, R., Eboli, L., \&Mazzulla, G. (2013). Perceived service quality in bus transit service: A structural equation approach. Transport Policy, 29, 219-226. doi: 10.1016/j.tranpol.2013.07.001.

[5] Diana, M. (2012). Measuring the satisfaction of multimodal travelers for local transit services in different urban contexts. Transportation Research Part A: Policy and Practice, 46 (1), 111. doi: 10.1016/j.tra.2011.09.018.

[6] C., Dhingra. (2011). Measuring Public Transport Performance: Lessons for Developing Cities. Sustainable Urban Transport Technical Document. Retrieved from http://www.bmz.de/

[7] Eboli, L., \& Mazzulla, G. (2007). Service Quality Attributes Affecting Customer Satisfaction for Bus Transit. Journal of Public Transportation, 10 (3), 21-34. doi: 10.5038/23750901.10.3.2

[8] Eung, N., \&Choocharukul, K. (2018). Modeling Frequency of Using Informal Public Transport and Public Bus: A Case Study in Phnom Penh, Cambodia. Engineering Journal, 22 (3), 109-122. doi: 10.4186/ej.2018.22.3.109.

[9] F. W., Panjaitan. (September 2016). Understanding Intermediate Public Transport (IPT) as the Mode of Choice in Jakarta, Indonesia. 1-91. Retrieved from hdl.handle.net/2105/42304.

[10] Hashim, R., Mohamad, S., Haron, S., Hassan, F., Hassan, N., \& Kasa, A. (2013). Student satisfaction with the campus bus services at UiTM Shah Alam, Malaysia. 2013 IEEE Business Engineering and Industrial Applications Colloquium (BEIAC). doi: 10.1109/beiac.2013.6560227.
[11] Horsu, E. H. \& Yeboah, S. T. (2019). Influence of Service Quality on Customer Satisfaction: A Study of Minicab Taxi Services in Cape Coast, Ghana. 3. 1451-1464.

[12] Islam, Md \& Hasan, Md. Mehrab \& Das, Prasanjit \& Rahman, Farzana. (2018). ASSESSING BUS SERVICE QUALITY BASED ON PUBLIC PERCEPTION: A CASE STUDY IN CHITTAGONG CITY.

[13] Joewono, T. B., \& Kubota, H. (2007). User satisfaction with paratransit in competition with motorization in Indonesia: anticipation of future implications. Transportation, 34 (3), 337-354. doi: 10.1007/s11116-007-9119-7.

[14] J. W., Park, R., Robertson, \& Lung, C., Wu. (20 july 2004.). The effect of airline service quality on passengers' behavioral intentions: A Korean case study. doi: https://doi.org/10.1016/j.jairtraman.2004.06.001

[15] L. L., Berry, A. P., Parasuraman, \& V. A., Zeithaml. (january 1990). Five Imperatives for Improving Service Quality. Sloan Management Review 31 (4): 9-38.

[16] Marcucci E., (2011), Scelte di trasporto e modelli a scelta discreta, Collana Economia e Politica Industriale, Franco Angeli, Milano. ISBN 978-88-568-3172-6.

[17] Masud-Ul-Hasan, M., Rahman, M. H., \&Rana, M. (2015). Identifying Service Quality Attributes and Measuring Customer Satisfaction of Dhaka-Pabna Route Public Bus Service. Asian Business Review, 5 (2), 72. doi: 10.18034/abr.v5i2.471.

[18] M. B., Adelman, \& A. C., Ahuvia. (March 1995). Social Support in the Service Sector: The Antecedents, Processes, and Outcomes of Social Support in an Introductory Service, Volume 32 (Issue 3), 273-282. doi: https://doi.org/10.1016/0148-2963(94)00052-G

[19] M. D., Meyer, \& E. J., Miller. (2001). urban travel and transportation system characteristics: A systems perspective. Urban Transportation Planning: A Decision-oriented Approach, McGraw-Hill series in transportation, 2nd ed, 89178.

[20] M., Fortini. (2000). Linee guida metodologiche per rilevazioni statistiche. Nozioni Metodologiche Di Base E Pratiche Consigliate per Rilevazioni Statistiche Dirette O Basate Su Fonti Amministrative.

[21] Md. Masud-Ul-Hasan, Md. Hasebur Rahman \&Masud Rana. (2015). Identifying Service Quality Attributes and Measuring Customer Satisfaction of Dhaka-Pabna Route Public Bus Service.

[22] Oliver, R. L. 2014. Satisfaction: A Behavioral Perspective on the Consumer. London, NY: Routledge. deOña, J., R. de Oña, and F. J. Calvo. 2012. "A Classification Tree Approach to Identify Key Factors of Transit Service Quality." Expert Systems with Applications 39 (12): 11164-11171.

[23] Parasuraman, A., Zeithaml, V. A., \& Berry, L. L. (1985). A Conceptual Model of Service Quality and Its Implications for Future Research. Journal of Marketing, 49 (4), 41-50. doi: $10.1177 / 002224298504900403$.

[24] Park, J., Robertson, R., \& Wu, C. (2004). The effect of airline service quality on passengers' behavioural intentions: a Korean case study. Journal of Air Transport Management, 10 (6), 435-439. doi: 10.1016/j.jairtraman.2004.06.001. 
[25] Paulley, N., Balcombe, R., Mackett, R., Titheridge, H., Preston, J., Wardman, M. White, P. (2006). The demand for public transport: The effects of fares, quality of service, income and car ownership. Transport Policy, 13 (4), 295-306. doi: 10.1016/j.tranpol.2005.12.004.

[26] Radam, Iphan \& H Kartadipura, Retna \& Yuliana, Candra. (2014). Passengers' Perception of Service Quality of Intercity Public Transport: A Banjarmasin Case Study. IOSR Journal of Mechanical and Civil Engineering. 11. 11-16. 10.9790/168411651116

[27] V. K., PHUN, P., PHENG, \& T., YAI. (December 26, 2015). Using Ordered Probit Modeling to Assess Perceived Bus Performance in Phnom Penh. doi: https://doi.org/10.11175/easts.11.1155

[28] Xiaokun (Cara) Wang \& Kara M. Kockelman. (2009).
APPLICATION OF THE DYNAMIC SPATIAL ORDERED PROBIT MODEL: PATTERNS OF OZONE CONCENTRATION IN AUSTIN, TEXAS.

[29] Kokku Randheer, Ahmed A. AL-Motawa, and Prince Vijay, (2011). Measuring Commuters' Perception on Service Quality Using SERVQUAL in Public Transportation.

[30] Monticone and Bierlaire, (2011). Adjectives qualifying individuals' perceptions impacting on transport mode preferences.

[31] Currie, Graham, Wallis, Ian. (2008). Effective ways to grow urban bus markets - a synthesis of evidence. Journal of Transport Geography, Volume 16, Issue 6, pp 419-429.

[32] Gable, G (1994). Integrating case study and survey research methods: an example in information systems. Eur J Inf Syst 3, 112-126 https://doi.org/10.1057/ejis.1994.12 